\title{
Resiliência e insucesso escolar: uma reflexão sobre as salas de apoio à aprendizagem
}

\section{Resilience and lack of school success: a reflection about learning support rooms}

\author{
Francismara Neves de Oliveira* \\ Universidade Estadual de Londrina - UEL, Londrina, Paraná, Brasil \\ Lino de Macedo** \\ Universidade Estadual de São Paulo- USP, São Paulo, São Paulo, Brasil
}

\begin{abstract}
RESUMO
Relacionamos neste artigo resiliência e dificuldades de aprendizagem escolar e objetivamos analisar as significações de dificuldades de aprendizagem de 30 alunos, 8 professores e um membro do núcleo de educação além dos documentos normativos da sala de apoio à aprendizagem. Como pesquisa descritiva - estudo de casos múltiplos - realizamos observação, entrevista e análise documental. 0 período de coleta dos dados foi de 2 meses, 8 horas semanais, 4 horas em cada uma das duas escolas estaduais participantes do estudo, no município de Londrina-PR. Nossos resultados indicaram que as significações de alunos e professores sobre dificuldades de aprendizagem são correspondentes às dos documentos, nas quais persiste a culpabilização do aluno e de sua família pelo não aprender. A ausência de estratégias mais resilientes para o aprender tem relação com os procedimentos dos alunos em situações de aprendizagem, com o funcionamento das salas de apoio e proposições metodológicas não promotoras de resiliência neste contexto.
\end{abstract}

Palavras-chave: Educação; Dificuldades de aprendizagem; Resiliência, Significações; Fracasso escolar.

\begin{abstract}
This study comprises resilience and school learning difficulties. Objective is to analyze the meaning of 30 students, 8 teachers, and the one present in normative documents of the learning support room. We have selected the study of multiple cases, of a descriptive research. In addition to the observation of support rooms' activities, we carried out interviews and document analyses. The data were collected within 2 months, 8 hours a week, 4 hours for each state school in Londrina-PR. The results indicate that the significations of students and teachers correspond to those found in documents, in which students and their families are laid the blame for learning deficiencies. The lack of more resilient learning strategies are related to the procedures of students in learning situations, the work of support rooms and methodological propositions whose are not resilience promoting in this context.
\end{abstract}

Keywords: Education; Learning difficulties; Resilience; School failure. 


\section{Introdução}

O presente artigo é parte da pesquisa de pós-doutorado da primeira autora, orientada e partilhada pelo segundo autor. O estudo objetivou analisar as significações de dificuldades de aprendizagem para professores e alunos envolvidos nas salas de apoio à aprendizagem, bem como relacionar tais significações à construção da resiliência em escolares. Partimos do pressuposto de que há diferentes modos de compreender 0 não aprender, reveladores das concepções pertinentes às distintas abordagens teórico-metodológicas subsidiadoras da questão.

Entretanto, a despeito de diferentes enfoques no estudo deste fenômeno, é recorrente a indicação nas pesquisas atuais, da necessidade de romper com a culpabilização do aluno e de sua família pelo insucesso escolar ao mesmo tempo em que são enfatizados fatores multicausais tanto na produção quanto na superação do insucesso escolar. (COLLARES; MOYSES, 1996; MARTINI; BORUCHOVITCH, 1999; CHARLOT, 2001; SMITH; STRICK, 2001; SOUZA; SISTO, 2001; PROENÇA, 2002; ANDRADA, 2003; CHABANNE, 2006; CAMARGO, 2008; LUZ, 2008; ZIBETTI; SOUZA; QUEIRÓZ, 2010). Paralelamente, as teorias que estudam o desenvolvimento humano, têm apresentado forte ênfase nos contextos e sistemas nos quais o indivíduo está inserido para compreender um dado fenômeno. (BRONFENBRENNER, 1980; DESSEN, 2005).

Considerando este contexto, interessou-nos estudar uma temática recente na Psicologia do Desenvolvimento Humano, a resiliência. Advinda das discussões da Psicologia Positiva que postula os indicadores saudáveis necessários aos sistemas adaptativos no processo de desenvolvimento humano, o estudo da resiliência e em especial dos mecanismos protetivos, corrobora a inversão do predomínio dos aspectos negativos, patológicos, de desordens e de inadaptação humana presentes nos referenciais teóricos da psicologia em geral. (YUNES, 2003; PASSARELI; SILVA, 2007).

$O$ constructo da resiliência no estudo do desenvolvimento humano tem sofrido alterações nos últimos anos. As pesquisas revelam uma mudança de postura no que concerne a compreensão dos fatores de risco e de proteção como condição de desenvolvimento e de estabelecimento de relações nos diferentes microssistemas envolvidos neste processo. (DE ANTONI; KOLLER, 2000; CECCONELLO, 2003; LARANJ EIRA, 2007).

Nesse momento de nossa análise, passamos a discorrer sobre estes constructos para, a posteriori, localizarmos uma relação que nos interessa como objeto de estudo, a construção da resiliência em alunos frequentadores de um programa oficial de trabalho com as 
dificuldades de aprendizagem, da rede estadual de ensino (PR), denominado salas de apoio à aprendizagem.

\section{Resiliência: constructos teóricos sustentadores}

Desde a compreensão inicial do conceito originário na Física, relativo à capacidade que apresenta um produto de não sofrer deformação após sofrer pressão, passando pela ênfase dada à capacidade inerente ao sujeito para o enfrentamento da realidade, o conceito de resiliência chega à compreensão atual que enfatiza as condições de sua construção e as possibilidades preventivas e interventivas envolvidas na superação das adversidades. (MELILLO; OJEDA, 2005; ASSIS; PESCE; AVANCI, 2006).

Os estudos desenvolvimentais contemporâneos concebem as adversidades como variáveis interdependentes de um contexto social que envolve fatores políticos, ambientais, sociais, econômicos, familiares, genéticos e culturais. Fala-se, portanto em mecanismos de risco e não apenas em fatores de risco que poderiam ser concebidos isoladamente. Ao denominarem mecanismos de risco, tais estudos apontam para a multiplicidade de elementos na constituição de um fenômeno. (PALLUDO; KOLLER, 2005; LARANJ EIRA, 2007).

Ainda que os estudos mais atuais percebam um contexto integrado na produção dos mecanismos de risco, o que sem dúvida se constitui em avanço para a pesquisa nesta área, é possível identificar um predomínio da relação entre resiliência e adaptação do indivíduo ao meio. Por um lado, a ênfase recai sobre os prováveis acontecimentos ameaçadores e por outro, reforça a competência do sujeito para superar as condições adversas. É possível perceber, ainda que de forma sutil, a presença de uma concepção enaltecedora das adversidades. Acentua-se que alguns indivíduos ou grupos, passando por situações adversas constroem mecanismos resilientes enquanto outros sucumbem aos riscos.

É como se a ausência de resiliência indicasse uma "falha" impedidora da construção no percurso formativo do sujeito. Subjaz a este modo de conceber a resiliência, a ênfase nos fios da trama que passam a ser minuciosamente analisados (e localizados no sujeito) enquanto são ignoradas as teias e os teares que teceram a trama. Tavares et al. (2002) alertam para o fato de que nesses estudos, a ênfase é dada às lacunas que impedem a adaptação do indivíduo ao meio, ao que o torna vulnerável e pouco resiliente.

Laranjeira (2007, p. 3) em pesquisa bibliográfica confirma essa relação entre adaptação ao meio e resiliência e analisa que os estudos "[...] cada vez mais se debruçam sobre critérios particulares ligados ao tema $[\ldots]$ " 
Tomamos por exemplo a concepção de Sapienza e Pedromônico (2005, p. 214) que assinalam: "quando muitas situações de risco se associam, elas dificultam o cumprimento da agenda desenvolvimental, a aquisição de habilidades e o desempenho de papéis sociais".

Em nosso entender, a afirmação da existência de uma "agenda desenvolvimental" que é impedida pelos riscos, pode levar a uma supervalorização do risco e sua localização em um dado grupo ou população. Nesta mesma linha de análise, é possível identificarmos como essa concepção resvala na "teoria da carência cultural", discutida amplamente por Patto (1999). Citamos como exemplo, o estudo de Haggerty et al. (2000) quando enfatizam que as famílias são em sua maioria, sujeitas a múltiplos riscos, porém, consideram que os filhos de famílias pobres são mais afetados pelas condições adversas dos pais e nomeiam essas adversidades: pobreza, discórdia e separação, problemas de saúde e desemprego. É como se tais condições, tidas como mecanismos de risco (porque ocorrem associadas), constituíssem o conjunto de características próprias às famílias cujo nível socioeconômico é baixo.

Quanto aos fatores protetivos, Sapienza e Pedromônico (2005, p. 211) comentam que dizem respeito à "personalidade da criança, à família, às experiências de aprendizagem, à exposição reduzida ao risco e às experiências compensadoras proporcionadas, por exemplo, por um ambiente escolar favorável." Este modo de entender os fatores protetivos os localiza no indivíduo e em seus contextos imediatos.

Em contraposição a esse modo de conceber a resiliência, encontramos na literatura a compreensão dos mecanismos de risco e de proteção estudados nas relações entre diferentes microssistemas. (DE ANTONI; KOLLER, 2000; CECCONELLO, 2003; PALUDO; KOLLER, 2005; LARANJEIRA, 2007). Tais discussões são subsidiadas especialmente pelos eixos epistemológicos da Psicologia Positiva (SELIGMAN; CSIKSZENTMIHALYI, 2000; SELIGMAN, 2004; SELIGMAN; STEEN; PARK, 2005) e da Abordagem Bioecológica do desenvolvimento humano (BRONFENBRENNER, 1980).

Nessa linha, Pinheiro (2004) estabelece uma crítica aos estudos que trataram os fatores protetivos como condições do sujeito ou do que está diretamente relacionado a ele. Aponta que mesmo considerando o avanço na discussão dos fatores protetivos, os estudos centram-se no sujeito e em seu entorno. Elencou os seguintes eixos na ordem de importância apresentada nas obras que consultou: condições do próprio sujeito, condições familiares, redes sociais, estilos parentais e práticas educativas na família.

Grünspun (2003) analisando sujeitos expostos a repetidas e intensas experiências de risco, define os fatores protetivos como barreiras ao risco que favorecem o desenvolvimento saudável do indivíduo e os 
localiza mais nas interações que nas condições individuais, tais como o suporte social e o autoconceito positivo. Assim como fatores de risco articulados entre si constituem mecanismos de risco e seu poder destrutivo ou de promoção de vulnerabilidades aumenta pela coatuação, o mesmo processo se dá com os fatores protetivos. Diferentes fatores resilientes associados indicam estruturação protegendo o sujeito na exposição aos riscos.

Morrison e cols. (2002) consideraram que os fatores protetivos formam uma rede e que esta pode se tornar favorável à extinção de comportamentos mesmo daqueles definidos como anti-sociais.

Posto isto que analisa não exaustivamente, mas apresenta dois grupos de pesquisas e o tom dado recorrentemente nos estudos sobre resiliência, apresentamos o posicionamento que assumimos na presente discussão que é de discordância com o entendimento de que a resiliência é condição própria ao indivíduo para superar adversidades que são do meio.

\section{Resiliência: uma possibilidade de pensá-la à luz da teoria Piagetiana}

Apropriamos-nos dos pressupostos da teoria da equilibração (PIAGET, 1975) para pensarmos a resiliência. A relação que fazemos implica na consideração de que mecanismos de risco e fatores protetivos constituem um sistema de complementaridade dialética, do modo como é entendida na teoria piagetiana: uma relação de interdependência entre sistemas articulados, em circularidade. (PIAGET, 1980). Assim, acertos e erros, ensino-aprendizagem, relação professor-conhecimento-aluno, significações do não aprender para professores-alunos-sistema, podem ser analisados em interdependência, o que equivale a dizer que o equilíbrio (estado) precisa ser perturbado (processo). Em outras palavras, o estado de equilíbrio nem sempre é positivo ou favorável. É possível um estado de equilíbrio pautado na ocultação das dificuldades de aprendizagem, por exemplo.

Isto permite compreender que um aluno pode ser resiliente e ainda assim, apresentar dificuldades para aprender. Ou seja, as estratégias que utiliza, bem como as assimilações dos objetos de conhecimento, os esquemas que emprega na resolução de problemas podem ser adequados a uma avaliação que desconsidera o processo e supervaloriza o produto da aprendizagem. Um aluno com dificuldade de aprendizagem que cola, copia, seduz os colegas nos trabalhos em grupo pode ser considerado resiliente porque responde satisfatoriamente do ponto de vista do resultado. Entretanto, se avaliado em seu processo de construção do conhecimento, apresenta 
uma dinâmica de aprendizagem pouco resiliente no que diz respeito ao aprender.

Nesse sentido, a resiliência implica em homeostase e homeorrese. A homeostase diz respeito às regulações necessárias para o retorno ao estado de equilíbrio perdido pelo organismo durante a perturbação, por exemplo, as ações necessárias à manutenção da pressão arterial quando alterada. A homeorrese por sua vez implica na transformação, criação, reequilibração, cujo estado de equilíbrio não é o mesmo anterior por conta das transformações e criações advindas do novo (PIAGET, 1975).

Nesse sentido, três diferenciações desta perspectiva com as demais são possíveis no entendimento da resiliência: a primeira reside no fato de que as interações referem-se às totalidades formadas por elementos positivos e negativos em recíprocas relações. Olhar para a resiliência partindo dessa premissa supõe que aspectos fracos e fortes (vulnerabilidade e resiliência, aprender com dificuldades e sem dificuldades) constituem um mesmo processo em contínua interação e não por oposição. Por essa razão dizemos que a vulnerabilidade não é do sujeito ou do meio, assim como não está nele (sujeito ou meio), a priori, a resiliência. $O$ balanço entre fatores protetivos e risco define a resiliência diante de situações de aprendizagem.

Na perspectiva piagetiana, os conflitos cognitivos são possibilidades de crescimento por meio da interação. As interações criam conflitos, geram perturbações, engendram problemas a serem solucionados. Em nosso entendimento não está no risco a condição de construir resiliência, nem no sujeito à priori, para responder ao problema, mas sim na perturbação do sistema cognitivo diante do conflito gerado pela constatação da insuficiência de esquemas para a resolução do conflito, o que obriga a construção de fatores resilientes. Construir fatores protetivos no processo de equilibração-desequilibração é tornar-se resiliente. Assim, a resiliência pode ser entendida como uma qualidade de interação por meio da qual riscos e fatores protetivos são transformados de modo interdependente, por processo.

Ou seja, há um continuum em andamento no qual a vulnerabilidade e a resiliência constituem em maior ou menor grau respectivamente a forma de lidar com o problema.

A segunda possibilidade de diferenciação, decorrente da primeira, no entendimento da resiliência ancora-se no conceito dado por Piaget (1936, p. 13) para a adaptação, no qual distingue adaptação-estado, da adaptação-processo. Para o autor, a adaptação-estado refere-se ao equilíbrio entre assimilações e acomodações, entretanto, a principal forma de adaptação é a adaptação-processo, que permite descrever progressos do conhecimento, justamente porque vai além da 'plasticidade' adaptativa do sujeito às demandas e pressões do meio. Extingue-se a necessidade de deformar o real (assimilação) em 
função do próprio ponto de vista. Não há mais necessidade de a acomodação se moldar aos dados exteriores, passando a se constituir uma experiência inteligente de fato. (MONTANGERO; MAURICENAVI LLE, 1998).

Isto equivale a considerar, por exemplo, que localizar mecanismos de risco e de proteção em um determinado grupo e generalizar seus resultados não é eficiente na promoção da resiliência. Justamente por não se tratar de um estado adaptado ao meio e sim de um processo adaptativo, a construção depende de elementos do contexto específico, das inter-relações sistêmicas envolvidas.

Em resumo, ao discordarmos com a cisão entre mecanismos de risco e de proteção, enfatizamos as relações intersistêmicas na construção de fatores protetivos que se coadunam aos mecanismos próprios à vida, ao processo de desenvolvimento, às aprendizagens escolares, às interações entre pares, às afirmações e negações que nos movem. A terceira possibilidade de diferenciação que fazemos é que os fatores protetivos não estão no sujeito, mas dependem de uma construção que lhe é própria. A ação é por sua natureza transformadora, em duas dimensões: do mundo e de si mesma. A ação é esquematizadora e envolve as implicações - localizando as relações parte-todo. (PIAGET, 1977, 1978).

A ação estruturante do sujeito permite construção de estratégias de enfrentamento que não existiam nem na situação em si e nem no meio e que diante do desequilíbrio foram desencadeadas no processo de conhecer. Os fatores protetivos e de risco engendram e denunciam o trabalho das invariantes funcionais do desenvolvimento: assimilações e acomodações e não são suficientes em si mesmos, pois implicam na tomada de consciência da própria ação.

Analisando o conceito dado por (PIAGET, 1977; 1978) ao processo de apropriação da ação - fazer e compreender - (BECKER, 2001) comenta que a tomada de consciência significa um processo de apreensão do mundo, dos modos de construí-lo, de transformá-lo e de apreensão de si mesmo. Segundo o autor, a apreensão do mundo e de si mesmo é correlata, por isso objetivação e subjetivação como processos interdependentes.

No entendimento da importância da ação do sujeito na construção de mecanismos protetivos, as significações assumem relevância neste artigo, pois na concepção adotada por nós, um objeto é o que ele significa ao sujeito e ele é significado pela estrutura (forma) de pensamento a ele aplicado. (PIAGET; GARCIA, 1987).

É nesse sentido que as significações acerca do não aprender podem ser relacionadas à resiliência, pois constituem fatores protetivos ou risco a depender do contexto no qual emergem e são postas em relação recíproca. Além disso, as significações do não aprender permeiam o processo de trocas intersistêmicas entre risco e proteção. E por fim, embora as significações possam ser depreendidas das 
ações do sujeito no meio, elas não são produções "puras" do sujeito, nem se referem à simples incorporação pelo sujeito, dos significados produzidos no meio que o cerca.

Antes, porém de discutirmos as significações do não aprender para os alunos e professores envolvidos na sala de apoio, recorte da presente discussão, analisemos o programa instituído pela Secretaria Estadual de Educação do Paraná, denominado salas de apoio à aprendizagem (PARANÁ, SEED, resolução 371/2008).

\section{Programa Sala de Apoio à Aprendizagem- lócus do estudo}

O programa tem a finalidade de atender a quinze mil alunos em todo - Estado com aproximadamente oitocentas turmas funcionando no sistema de contraturno. O objetivo principal das salas de apoio é o enfrentamento das dificuldades apresentadas pelos alunos, com relação à aprendizagem de Língua Portuguesa (oralidade, leitura, escrita) e Matemática (formas espaciais e quantidades nas suas operações básicas e elementares). (PARANÁ RESOLUÇÃO 371- CNE 04/98, instrução no 022/2004).

Se considerarmos que a política educacional aparentemente ou intencionalmente é positiva, uma contradição se impõe: como são avaliados os desequilíbrios no processo de aprendizagem dos alunos frequentadores das salas de apoio? Ora são negados, ora são considerados problema. Atitudes de afirmação são desencadeadas: criam-se programas de contraturno, professores são contratados, positivam-se as estatísticas escolares, a permanência do aluno na escola é garantida pela promoção automática. Entretanto, os resultados não são favoráveis aos alunos tidos como vulneráveis, pois são colocados em um meio escolar ainda mais vulnerável cujos elementos não concorrem para a promoção de resiliência. A proposta de aprendizagem, as significações acerca do não aprender, a postura do professor, a escola como ambiente, os recursos oferecidos não promovem resiliência, apenas indicam que o aluno não é resiliente.

Uma relação "fraca" com o aprender em um meio "vulnerável" é diferente de uma relação "forte" com o aprender, ainda que o meio seja vulnerável. As estratégias de construção de resiliência passam a ser frágeis ou empobrecidas quando este processo é desconsiderado. Por exemplo, passar colando nas provas, ser avaliado por instrumentos que não "verificam" o aprendido, a sedução e/ou a vitimização, a aprovação por conselho de classe porque o comportamento é bom, constituem mecanismos resilientes, entretanto não são adequados ao processo de aprender. São resilientes porque funcionam como estratégia de sobrevivência imediata, entretanto não favorecem o processo, muito embora possam garantir um "produto" tido como favorável (a aprovação). 
Aprender é a melhor forma de enfrentar a vida, ações acadêmicas no contexto escolar constituem-se demonstração de resiliência, entretanto o aluno parece distante de conceber deste modo sua passagem pela escola. Por outro lado, a escola ao (des)responsabilizar-se pelo não aprender também não se torna ela mesma resiliente e favorecedora dessa construção em seu espaço de atuação. (TAVARES, et al. 2002)

\section{Método}

A pesquisa, de natureza qualitativa desenvolveu-se na perspectiva de estudo descritivo. De acordo com Barros e Lehfeld (2000, p. 70) "A pesquisa descritiva engloba dois tipos: a pesquisa documental e/ou bibliográfica e a pesquisa de campo". O Estudo de Campo é definido como "[...] realizado por meio da observação direta das atividades do grupo estudado e de entrevistas com informantes para captar as explicações e interpretações do que ocorre naquela realidade". (HEERDT, 2009). Empregamos estas duas formas (documental e de campo) na especificidade do estudo de casos múltiplos.

Segundo Yin (2005) e Martins (2006) essa é uma modalidade que permite que a situação de pesquisa seja replicada simultaneamente nas unidades escolhidas, preservando-se as características de coleta e análise em cada caso específico. Os resultados segundo os pesquisadores são mais fidedignos do que os estudos de casos simples, por conta da lógica da replicação simultânea que permite que os dados sejam agrupados, se ampliem, sem perder a característica de profundidade de um estudo de caso.

Como questões norteadoras elegemos: Quais as relações entre resiliência, significações do não aprender e insucesso escolar? Quais as significações de alunos e professores sobre as dificuldades de aprendizagem na sala de apoio?

Participaram do estudo 30 alunos que frequentam o 60 ano do Ensino Fundamental de duas escolas da rede estadual em um município paranaense (15 alunos em cada escola). O critério de seleção/exclusão empregado para constituir a amostra de alunos foi o fato de frequentarem a sala de apoio à aprendizagem que funciona em turno contrário ao da sala regular e que reúne apenas os alunos encaminhados a este espaço, classificados pela escola como tendo dificuldades de aprendizagem em Língua Portuguesa e Matemática. Dos 30 alunos participantes, 18 eram do sexo masculino e 12 do sexo feminino. Do número total da amostra, 15 ( 11 meninos e 4 meninas), tinham histórico de reprovação, sendo 12 deles reprovados no 60 ano ( 3 meninas e 9 meninos) e 3 retidos no primeiro ciclo do ensino fundamental ( $10-50$ ano, todos meninos). A idade dos alunos 
participantes ficou entre 11 anos e 3 meses e 15 anos e 5 meses) no momento da coleta de dados.

A amostra de professores foi constituída adotando-se o seguinte critério de seleção/exclusão: dois professores da sala regular (um de Língua Portuguesa e um de Matemática) de cada escola, responsáveis por selecionar e encaminhar os alunos com dificuldades de aprendizagem para a sala de apoio. Dois professores que atuavam na sala de apoio sendo um de língua Portuguesa e um de Matemática. Participaram, portanto 8 professores ( 4 de cada escola, 7 do sexo feminino e 1 do sexo masculino). O tempo de atuação na sala de apoio oscilou entre 6 meses e quatro anos. Além dos professores e alunos, participou do estudo um membro da coordenação do programa no Núcleo Regional de Educação do mesmo município paranaense, do sexo feminino e que exerce essa função desde a implantação do programa em 2004.

O Procedimento de Coleta de Dados foi aplicado de modo semelhante em cada unidade de ensino tal como sugere o modelo de estudo de casos múltiplos (YIN, 2005; MARTINS, 2006): observação sistemática das aulas nas salas de apoio, objetivando depreender das ações desencadeadas, as significações atribuídas por professores e alunos ao não aprender. A observação ocorreu durante dois meses, duas vezes por semana em cada escola, 8 horas semanais, durante as aulas de Língua Portuguesa e de Matemática. Para atender a este objetivo, descrevemos em diário de campo as ações observadas na sala de apoio (professores e alunos), por meio do registro das atividades propostas, seu desenvolvimento e o modo como os alunos dela se apropriavam, além da fala dos envolvidos.

Além das observações, utilizamos entrevistas semi-estruturadas para os professores e alunos. Essas entrevistas objetivavam investigar como significavam a sala de apoio à aprendizagem enquanto programa, que significados foram atribuídos às dificuldades de aprendizagem e como se percebiam participantes desse espaço. Os participantes foram entrevistados individualmente com horários previamente agendados nos dois meses que se seguiram à observação, nas duas escolas envolvidas.

Os critérios de coleta de dados próprios ao estudo de casos múltiplos, foram seguidos: uso de várias fontes de evidência (vários indicativos de um mesmo fenômeno), construção de uma base de dados (descrição das observações), formação de uma cadeia de evidências mostrando relação direta entre os dados e o ambiente no qual foram colhidos, no caso a sala de apoio. Seguidos estes critérios, foi possível integrar os dados das observações aos dados das entrevistas, elaborando categorias ou eixos norteadores teoricamente fundamentados. Nestes eixos, são discutidos apenas os aspectos que se fizeram presentes tanto na observação quanto na entrevista, articuladamente. Os aspectos que se evidenciaram na observação, 
mas que não emergiram nas falas dos entrevistados foram ignorados, bem como o inverso, apareceram na fala dos entrevistados, mas não foram depreendidos nas observações, foram excluídos da análise.

Por fim cabe anunciar que no estudo de casos múltiplos o que se procura generalizar são as proposições teóricas e não as proposições sobre as populações (YIN, 2005). Assim, na análise de nossos dados as significações do não aprender e das salas de apoio à aprendizagem acham-se destacadas e não a amostra (professores e alunos) das escolas investigadas, tendo em vista que esse processo de captura dos dados ocorreu em um longo período, de Março a Julho de 2009 e oportunizou que os eixos de análise aqui apresentados se constituíssem com dados documentais, de entrevista e de observação, articulados teoricamente.

\section{Análise dos resultados}

Organizamos os resultados de nosso estudo em dois eixos de análise: concepção de dificuldades de aprendizagem presente nos documentos normativos e nos procedimentos adotados para o encaminhamento e desenvolvimento do trabalho na sala de apoio e significação atribuída por professores e alunos para as dificuldades de aprendizagem na sala de apoio. A estruturação dos eixos seguiu as diretrizes do estudo de casos múltiplos segundo as quais, os dados são apresentados de modo a compor links de discussão que se articulam entre si e revelam o ambiente no qual foram constituídos. (MARTINS, 2006)

\section{Concepção de dificuldades de aprendizagem evidenciada nos documentos e na constituição das salas de apoio}

A política educacional que rege o trabalho na sala de apoio apresenta alguns aspectos que sugerem reflexão: o modo como os professores são selecionados, a ausência de preocupação com teorias sustentadoras do trabalho com dificuldades de aprendizagem, ênfase nos aspectos administrativos em detrimento dos pedagógicos, a estrutura física das escolas como condição de oferta ou não das salas de apoio, as atribuições do professor e a avaliação feita aos alunos tanto no encaminhamento quanto na saída do programa. (PARANÁ RESOLUÇÃO 371 - CNE no 04/98, instrução no 022/2004).

Observamos que os elementos definidores estão pautados em uma concepção de dificuldades de aprendizagem particularizadora do não aprender e culpabilizadoras do aluno e de sua família. Zibetti, Souza e Queiróz (2010), refletem sobre o duplo papel que cabe ao aluno que detém em si um distúrbio que o impede de aprender: explicar 
por sua condição porque não aprende e eximir a instituição escolar desse sofrido processo de insucesso na aprendizagem.

A partir da instituição de salas de apoio em toda a rede escolar estadual paranaense, as escolas e os professores são cobrados quanto à minimização da estatística de reprovação e evasão. Os números relativos ao insucesso escolar são substituídos pelo número de "atendimentos" realizados aos alunos ditos com dificuldades de aprendizagem.

Alves (2007, p. 169) nos alerta: "O problema que resulta de se pensar o ensino a partir da busca de resultados (...) é que as decisões e práticas educativas, intrinsecamente ligadas a valores humanos e eminentemente políticos, são reduzidos a decisões técnicas". Nos documentos oficiais não há, por exemplo, preocupação em delimitar prazo mínimo de permanência do aluno na sala de apoio. Na realidade, o que observamos é uma rotatividade de alunos que não chegam a participar do programa sequer por um bimestre inteiro e são "liberados" para que sua vaga seja utilizada por outro aluno e aumente o número de participantes no programa. Afirma um dos entrevistados (professor 4):

\begin{abstract}
Eu procuro indicar alunos para as salas de apoio que não estejam tão comprometidos porque assim ele sai logo e eu uso a vaga dele para outro aluno que está com dificuldades leves e moderadas, pois as chances que esse tem de poder voltar para a sala regular e isso melhorar os índices é maior, né? Já o outro vai ter que ficar o ano inteiro na sala de apoio e não vai adiantar muita coisa.
\end{abstract}

Este modo de lidar com as dificuldades de aprendizagem na escola, apenas reforça estereótipos, solidifica a segregação e serve para comprovar que o problema é do aluno. (AQUINO, 1997).

Ao enfatizar, nas atribuições da equipe envolvida, muito mais os aspectos administrativos que pedagógicos do programa, a legislação por vezes exime o professor - quando atribui ao aluno o não aprender - e em outros momentos culpabiliza o professor. Afinal, o Estado oportuniza a condição de superação por meio das salas de apoio. Os resultados dependem do professor para que sejam positivos. Entretanto, são poucas as ações relativas à formação continuada, inexistem concursos específicos para atuação na sala de apoio, falta clareza nas atribuições dos envolvidos e no modo de atendê-las, inexistência de realização de encontros frequentes entre os envolvidos no programa visando a reflexão e a transformação das ações.

Em informação colhida junto ao representante do programa no núcleo estadual de educação, participante do estudo, havia sido oportunizado um encontro no ano (até o momento da coleta dos dados), cuja ênfase fora dada ao preenchimento das fichas de 
encaminhamento e de recebimento do aluno na sala de apoio. Assim, torna-se oportuno atribuir por vezes ao professor e a metodologia empregada e em outros momentos ao aluno e sua família (que não se interessam), o insucesso do processo de aprendizagem.

Bossa (2002) analisa que o fracasso escolar deve ser visto como transcendente às instituições estruturantes da singularidade do sujeito psíquico e deve orientar a reflexão sobre o modo de ser (das instituições que lidam com o aprender) que atravessa a história, o tecido social e as próprias instituições.

A amplitude do fenômeno é negada quando a culpabilização e a segregação ganham espaço. Collares e Moysés 1996, p. 26 assim analisam:

\footnotetext{
Pelo discurso dos professores e diretores, a sensação é que estamos diante de um sistema educacional perfeito, desde que as crianças vivam uma vida artificial, sem nenhum tipo de problemas, enfim, crianças que provavelmente não precisariam de escola para aprender. Para a criança concreta que vive neste mundo real, os professores parecem considerar muito difícil, se não impossível ensinar.
}

Quanto aos procedimentos de encaminhamento e desenvolvimento do trabalho na sala de apoio, pudemos observar que iniciaram funcionamento já nas primeiras semanas do ano letivo, partindo dos encaminhamentos dos professores das salas regulares de 5 a série ( 6 은 ano) e nem mesmo o critério de notas baixas que geralmente é adotado do segundo bimestre em diante, pôde ser o definidor da escolha do grupo que passou a frequentar a sala de apoio na terceira semana de aula.

O aluno passa a frequentar a sala de apoio como uma "punição" à sua inadequação frente ao modelo ideal de aluno que a escola e os professores almejam e reúne em si as impossibilidades de aprender (AMARAL, 1995).

Quando relacionamos estes dados ao conceito de resiliência percebemos porque analisá-la do ponto de vista adaptativo (de ajustamento do sujeito ao meio) não é suficiente. (LARANJEIRA, 2007). O aluno pode adaptar-se à sala de apoio, ser considerado apto a manter-se apenas na sala regular e ainda assim não aprender. Subjacente ao cumprimento da "tarefa" de superação dos índices de insucesso escolar está a significação atribuída aos fatores protetivos como externos ao aluno, presentes no meio, próprios à passagem do mesmo pela sala de apoio, significação presente nos documentos normativos, na postura do professor e na atitude do aluno frente ao aprender.

Nesse sentido é importante considerar a significação atribuída à sala de apoio que a exime da coparticipação no insucesso escolar dos alunos os quais agrega. Ao ter a chance de rever aquilo que não 
aprendeu e "desperdiçá-la", o estereótipo de mau aluno é reafirmado e desse modo a sala de apoio à aprendizagem ratifica a segregação. Além disso, a ênfase é dada ao conteúdo e não ao processo de aprendizagem do aluno. Em nosso entender, a sala de apoio pode constituir um espaço de ação e construção de fatores protetivos necessários ao enfrentamento dos desafios impostos pelo processo de aprendizagem.

Pesce, Assis, Santos e Oliveira (2004, p. 138) analisam a importância de promover fatores de proteção com crianças e adolescentes e afirmam que é necessário oportunizar o desenvolvimento de capacidades de enfrentamento, "empoderar a resiliência" e não apenas oferecer combate aos riscos e isto em todos os níveis de atuação e com enfoque multidisciplinar.

A construção de estratégias de ação mais resilientes não é oportunizada quando o contexto não é resiliente. Ou seja, uma escola que tenha em seus domínios um espaço oficial para o trabalho com as dificuldades de aprendizagem não pode prescindir de ser ela mesma, resiliente e exaltadora da resiliência em suas proposições.

Significar o aprender como uma rede ampla de relações intersistêmicas como discutimos anteriormente, permite olhar para os fatores protetivos como necessidade inerente ao processo de conhecer, portanto pertencente ao sujeito autônomo, peculiar ao seu pensamento e relativo aos desequilíbrios que a situação de conhecer evoca.

\section{Significações atribuídas por professores e alunos para as dificuldades de aprendizagem e para a sala de apoio.}

Tanto nas observações como na entrevista realizada, buscamos investigar as significações de dificuldades de aprendizagem por meio de questões que enfatizaram: definições de aprendizagem e de dificuldade de aprendizagem; principais características dos alunos com dificuldades de aprendizagem; as dificuldades mais frequentes apresentadas; causas que atribuem ao não aprender e os principais problemas que enfrentam no trabalho com as dificuldades de aprendizagem.

As respostas apresentadas pela maioria dos professores entrevistados indicam significações correspondentes à observação, no que concerne ao aprender tomado como acerto da escola enquanto o não aprender é definido como incapacidade do aluno. Está presente continuamente a tensão provocada pela diferença trazida pelos alunos que não aprendem e isto - a diferença - ao invés de ser considerada positiva, é tratada preconceituosamente. Conforme assinala França (1998, p. 209) "o preconceito é o grupo voltando a si mesmo, remetendo-se à semelhança". 
Apresentamos dois exemplos da fala de nossos entrevistados uma registrada na observação em sala e outra na entrevista realizada:

\begin{abstract}
(Professor 8) - Dificuldades de aprendizagem eu vejo assim... podem ser problemas extraclasse que afetam muito a capacidade de aprendizagem: o estilo de vida que ele tem, os problemas familiares, dificuldades financeiras, enfim, diversas situações que afetam no aprendizado.

(Professor 5 em comentário com os alunos em sala de aula) Vejam vocês. Olhem pra vocês mesmo. Estão na sala de apoio sempre aqueles que têm dificuldades extra-sala: problema familiar, falta de acompanhamento dos pais, desinteresse dos pais de acompanhar a vida escolar dos filhos. Então acho que isso dificulta bastante a vida de vocês.
\end{abstract}

É perceptível a significação de dificuldades de aprendizagem como algo produzido fora da escola, localizado no sujeito e em sua família ao passo que a escola é desconsiderada como co-produtora deste fenômeno. É como se a escola e em especial a sala de apoio apenas recebesse o problema (originado e desenvolvido em dimensões externas) e em nada fosse responsável a não ser por extingui-lo. Como o problema é ou está no aluno, ele passa pela sala de apoio e comprova que não reúne as condições necessárias ao aprender, mesmo em um programa específico para o trabalho com as dificuldades de aprendizagem, o que justifica sua segregação. (COLLARES; MOYSÉS, 1996; ZIBETTI; SOUZA; QUEIRÓZ, 2010).

Quando solicitamos as características dos alunos com dificuldades de aprendizagem, ouvimos (do participante 5): “Ou ele é muito tímido ou impulsivo ou agressivo ou disperso". Trata-se de um conjunto de atributos reunidos nessas definições, tidos como negativos que são localizados no aluno e parecem assumir um caráter permanente [...] "ele é" e isto o impede de agir, de pensar, de aprender. Apenas um dos professores (7) apresentou uma definição não polarizada entre escola e aluno/família e faz a seguinte reflexão: "A gente pergunta mais o que eles não sabem e pouco o que a gente pode fazer por eles como escola. Se não aprendem, não é só porque têm uma vida difícil. A escola também não atinge a necessidade de aprendizagem deles..." Quanto à concepção sobre a sala de apoio, os professores participantes foram unânimes em ressaltar seu valor positivo, mas destacamos a fala de um de nossos sujeitos, por ser ela contundente. Esta fala foi registrada no diário de campo por ter ocorrido em uma situação observada em sala na qual o professor (2) se dirige à pesquisadora e desabafa diante dos alunos:

- Digo aos alunos e aos seus familiares que o Estado está pagando professor particular para eles e que se não valorizarem, nada mais poderá ser feito. Depende deles (dos alunos e família) superarem ou não as dificuldades que têm. 
Essa oportunidade que o governo está dando é algo muito importante porque as famílias deles nunca conseguiriam pagar por esse serviço.

Essa concepção de que o aluno está em falta e traz consigo o problema, é percebida nos documentos normativos, no modo como são articulados os elementos que instituem as salas de apoio e podem ser percebidos também na concepção dos professores sobre as dificuldades de aprendizagem. E como veem tais questões os alunos?

Investigamos como concebem a sala de apoio e sua participação nela, as semelhanças e diferenças entre a sala regular e a sala de apoio; por que acham que foram escolhidos para a sala de apoio; que tipo de aluno pensam ser; o que a professora, a família e os amigos acham da participação na sala de apoio. Foi interessante percebermos que o discurso que os culpabiliza, já foi por eles incorporado. Dos 30 alunos entrevistados, a maioria (22) indica em suas respostas que se consideram indisciplinados (mau comportamento) e por essa razão "merecem" estar na sala de apoio. Embora afirmem que a sala de apoio é um lugar privilegiado para aprender, quando perguntamos o que é igual e o que é diferente entre os dois espaços, evidenciam muitas semelhanças e poucas diferenças entre a sala de apoio e a sala regular, o que confere com a repetição dos assuntos, da metodologia, das propostas de ensino, das atividades, constatação que registramos em nossas observações.

Quando perguntamos por que foram escolhidos para a sala de apoio, enfatizaram o quanto são maus alunos, o quanto são inadequados ao aprender. Eis algumas respostas: "Eu sou muito fraco e aqui eles ajudam a recuperar"; "moro com minhas tias, avós e mãe, acho que eles não incentivam"; "meus amigos tiram sarro, me chamam de burra"; "minha família acha que eu sou ruim".

Estas falas são reveladoras de quanto o processo de culpabilização já atingiu tais alunos fazendo com que incorporem o discurso de que têm um problema em si, ou em suas famílias. Gostaríamos de salientar a força dos estereótipos e lembrar como permeiam todos os espaços, desde as políticas educacionais responsáveis pela implantação e desenvolvimento de um programa como este que analisamos, até o modo como crianças e familiares se veem participantes deste processo.

Nesse sentido, nos apropriamos da reflexão trazida por Crochik e Crochik, 2005, p. 329-30: "Os alunos das classes consideradas fracas acabam por julgarem-se inferiores aos seus colegas e sentem-se responsáveis pelo próprio fracasso, podendo exibir, entre outras, atitudes consideradas inadequadas, como a indisciplina."

Entendemos que assim como a noção de sucesso escolar é produto cultural, as estratégias definidas como muito ou pouco resilientes 
também são culturalmente constituídas no cotidiano escolar (CHARLOT, 2001).

Retomamos aqui os três elementos diferenciadores da concepção de resiliência na perspectiva piagetiana, apresentados neste artigo: a relação entre aspectos positivos e negativos no aprender, constituintes de uma totalidade intersistêmica; os fatores protetivos e os mecanismos de risco co-dependentes na construção de resiliência diante das questões escolares; os indicadores de possibilidades de ação - fracos ou fortes - em situação específica de aprendizagem não são generalizáveis a todos os contextos de aprendizagem. Assim, mais importante do que discutir quais fatores são protetivos ou de risco ao aprender, é discutir as significações do aprender/não aprender neste espaço, pois elas são indicadoras do que é risco ou proteção na especificidade de um processo de aprendizagem.

E mais, uma estratégia de enfrentamento não é generalizável a todos os alunos que apresentam dificuldades para aprender ainda que frequentadores da mesma sala de apoio, justamente porque as significações construídas nesse espaço são diferenciadas. Mais uma vez são ressaltadas as significações presentes neste contexto, pois são constituintes das condições de construção às quais somos todos permeáveis. Por fim vale reafirmar que a resiliência é construção de autoria do sujeito em interdependência com os demais elementos que o constituem sujeito.

\section{Como últimas considerações - relações entre Resiliência e Dificuldades de Aprendizagem.}

Pudemos discorrer sobre a sutil, mas eficiente inviabilização de um processo de restabelecimento das condições de aprendizagem, a partir do momento em que a rotulação e a segregação encontram lugar, em detrimento da valorização de um processo de construção. Nossos dados neste estudo apontaram para descompassos entre os caminhos trilhados pelo aluno na construção do conhecimento e o que significa a aprendizagem na proposta governamental, para a escola que institui o programa, para o professor e para o aluno que o vivenciam. Indicaram a necessidade de um trabalho a ser adotado nas salas de apoio à aprendizagem que favoreça a ação autoestruturante do sujeito e nesse sentido, a construção de resiliência.

Como essa compreensão sobre resiliência pode lançar luz ao modo de olhar as dificuldades de aprendizagem na escola? Conforme discutimos neste artigo, a literatura que analisa a resiliência apesar de suas distintas ênfases, converge para a compreensão de um processo multicausal. Nesse sentido, o impedimento ou a condição de enfrentamento do que é adverso ao aprender, não podem ser polarizados nem no sujeito e ao que está diretamente relacionado a 
ele, nem no meio determinantemente, nem mesmo nos dois desarticuladamente.

Em discrepância a esta ideia, as discussões sobre insucesso escolar ainda se apresentam generalizadoras da condição incapacitante tanto de quem "detém" as dificuldades de aprendizagem "em si", quanto daqueles que devem lidar com o problema. A vitimização da escola, a instalação de um "não-lugar" do professor diante das dificuldades de aprendizagem de seus alunos, a crença no "não-saber" como resolver o problema, e a localização de problemas no aluno trazem em seu bojo, as significações das dificuldades de aprendizagem que ignoram a produção do fenômeno no cotidiano escolar. (CHARLOT, 2001).

Assim, relacionamos as significações do aprender e os fatores protetivos por meio dos quais a situação de aprendizagem pode ser considerada um processo resiliente. Em suma afirmamos que a resiliência em situação de aprendizagem escolar engendra mecanismos de risco e de proteção relacionados em intersistemas que devem manter-se em equilíbrio. Do equilíbrio construtivo, tal como concebido por Piaget (1975) dependem as condições de construção ou (re) construção que não estão localizadas isoladamente no sujeito, ou no meio, ou nos objetos de apropriação, ou na "ensinagem". Esta construção e reconstrução são muito mais marcadas pelo " $\mathrm{e}$ " que pelo "ou", o que denota a complexidade deste fenômeno.

Nessa ótica, o não aprender passa a atribuir significação à complexidade do processo na medida em que representa mais do que uma resposta insuficiente do aluno a uma exigência ou demanda da escola. As dificuldades de aprendizagem evidenciam, não apenas um processo insatisfatório, mas também as teias que o teceram. E, como sinaliza Charlot, 2001, p. 13 “o fracasso escolar é um objeto de pesquisa inencontrável." Como fenômeno, não chega puro até nós, dele depreendemos sua reprodução, suas significações, seus desdobramentos. Por essa razão, analisar o contexto de produção do insucesso no aprender é tão importante pois permite que nos apropriemos das significações produzidas no cotidiano escolar dado a conhecer.

Assim, mais uma vez afirmamos que a resiliência na escola é produzida contextualmente. Está a serviço do desenvolvimento do sujeito-autor e, nos fatores protetivos ou no risco, revelam-se copartícipes necessários ao enfrentamento das situações desequilibradoras próprias ao conhecer. Nesse sentido, é preciso percebermos que o insucesso na aprendizagem e os elementos que o envolvem estão em contínua interação o que supõe inclusive reciprocidade entre aspectos positivos e negativos, nas relações com o aprender.

Um projeto de trabalho com as dificuldades de aprendizagem na escola deve, portanto enfatizar a construção de interações favoráveis 
(resiliência) e não apenas o ajustamento do indivíduo ao meio, o que inevitavelmente inclui as significações construídas sobre o aprender e o não aprender, neste contexto.

A discussão que apresentamos não pretende ser conclusiva, pois se limita ao cotidiano das salas de apoio de duas unidades escolares em um município paranaense. Nesse sentido o estudo é indicativo da necessidade de novas pesquisas sobre a resiliência em contextos escolares e sobre o modo como um programa que se propõe a trabalhar a especificidade do não aprender pode ser (re) significado. Sugere ainda novas reflexões que possibilitem pensar a escola como espaço promotor de fatores resilientes em escolares incluídos em programas institucionais específicos, como é o caso das salas de apoio à aprendizagem e como estes estudos podem subsidiar o estabelecimento de políticas públicas de atendimento às dificuldades de aprendizagem na escola.

\section{Referências}

ALVES, W. F. Quando ensinar não é o mais importante: reflexões sobre o trabalho docente e o ofício do aluno no contexto atual. In: Olhar De Professor. Departamento de Métodos e Técnicas de Ensino, v. 10 n. 1. Ponta Grossa: Universidade Estadual de Ponta Grossa, 2007.

AMARAL, L. A. O Leão de Neméia - O desvio como ponto de partida. In: Conhecendo a Deficiência (em companhia de Hércules). São Paulo: Robe, 1995.

ANDRADA, E. G. C. Família, escola e a dificuldade de aprendizagem: intervindo sistemicamente. Psicologia Escolar e Educacional, Campinas, v. 7, n. 2. dez. 2003.

AQUINO, J. G. Erro e fracasso na escola - alternativas teóricas e práticas. 2a ed. São Paulo: Summus, 1997.

BARROS, A. J. de S.; LEHFELD, N. A. de S. Fundamentos de Metodologia Científica: um guia para a iniciação científica. São Paulo: Makron Books, 2000.

BECKER, F. Educação e construção do conhecimento. Porto Alegre: Artmed, 2001.

BOSSA, N. A. Fracasso Escolar: um olhar psicopedagógico. Porto Alegre: RS: Artmed, 2002.

BRONFENBRENNER, U. A ecologia do desenvolvimento humano: experimentos naturais e planejados (VERONESE, M. A. V. Trad.) Porto Alegre: Artes Médicas, 1980.

CAMARGO, H. C. Contraturno: um espaço de reflexão sobre a utilização de jogos em crianças com dificuldades de aprendizagem. 2008. 87f. Trabalho de Conclusão de Curso (Graduação em Pedagogia) - Universidade Estadual de Londrina, Londrina.

CECCONELLO, A. Resiliência e vulnerabilidade em famílias de situação de risco. 2003. 217f. Tese (Doutorado em Educação) - Departamento de Educação, Universidade Federal do Rio Grande do Sul, Porto Alegre. 
POLONIA, A. da C.; DESSEN, M. A.; SILVA, N. L. P O modelo bioecológico de Bronfenbrenner: contribuições para o desenvolvimento humano. In:

A ciência do desenvolvimento humano: tendências atuais e perspectivas futuras. Porto Alegre: Artmed, 2005. p. 71-79.

CHABANNE, J. L. Dificuldades de aprendizagem: um enfoque inovador do ensino escolar. São Paulo: Ática, 2006.

CHARLOT, B. Da relação com o saber: Elementos para uma teoria. Porto Alegre: Artmed, 2001.

COLLARES, C. A. L.; MOYSÉS, M. A. A. Preconceito no cotidiano escolar: ensino e medicalização. São Paulo: Cortez, 1996.

CROCHÍK, J. L.; CROCHÍK, N. Pesquisa e cotidiano escolar: e desempenho nas classes escolares homogêneas. Eccos - Revista Científica, São Paulo, v. 7, n. 2, p. 313-331, jul./dez. 2005.

DE ANTONI, C.; KOLLER, S. H. Vulnerabilidade e resiliência familiar: um estudo com adolescentes que sofreram maus tratos intrafamiliares. Revista da Faculdade de Psicologia da PUCRS, v. 31, n. 1, 39-66, 2000.

FRANÇA, S. A. M. Diferença e preconceito: a efetividade da norma. In: Diferenças e preconceito na escola: alternativas teóricas e práticas/Coordenação de Julio Groppa Aquino. - São Paulo: Summus, 1998. GRUNSPUN, $H$. Conceitos sobre resiliência. Disponível em: <http://www.cfm.org.br/revista/biolov1/seccao4.1.htm>. Acesso em: 20 de Abril de 2010.

HAGGERTY, R. F. J. (Org.). Stress, risk and resilience in children adolescents: process, mechanisms and interventions. New York: Cambridge University Press, 2000.

HEERDT, B.; BRANDT, C. F. Interações e Mediações possibilitadas pelas webquests. In: IX Congresso Nacional de Educação - e I I I Encontro Sul Brasileiro de Psicopedagogia - EDUCERE, 2009, Curitiba. Anais do IX Congresso Nacional de Educação - e III Encontro Sul Brasileiro de Psicopedagogia. Curitiba, Pontifícia Universidade Católica, 2009. p. 96779691.

LARANJEIRA, C. A. S. J. Do vulnerável ser ao resiliente envelhecer: revisão de literatura. Revista Psicologia: Teoria e Pesquisa, Brasília, v. 23, n. 3, jul./set. 2007.

LUZ, A. S. Dificuldades de aprendizagem e as salas de contraturno. 2008. 68f. Trabalho de Conclusão de Curso (Graduação em Pedagogia) Universidade Estadual de Londrina, Londrina.

MARTINI, M. L.; BORUCHOVITCH, E. As atribuições de causalidade, o desenvolvimento infantil e o contexto escolar. PSICO-USF, v. 4, n. 2, p. 23-36, 1999.

MARTINS, G. A. Estudo de caso: uma estratégia de pesquisa. São Paulo: Atlas, 2006.

MELILLO, A.; OJEDA, E. N. S. (Org.). Resiliência: descobrindo as próprias fortalezas. Porto Alegre: Artmed, 2005.

MONTANGERO, J.; MAURICE-NAVILLE, D. Piaget ou a inteligência em evolução - Sinopse cronológica e vocabulário. Porto Alegre: Artmed, 1998. MORRISON, G. M.; ROBERTSON, L.; LAURIE, B.; KELLY, J. Protective factors related to antisocial behavior trajectories. Journal of Clinical psychology, v. 58, n. 3, p. 277-290, 2002. 
PESCE, R. P.; ASSIS, S. G.; SANTOS, N.; OLIVEIRA, R. V. C. Risco e proteção: em busca do equilíbrio promotor de resiliência. Psicologia: Teoria e Pesquisa, Brasília, v. 20, n. 2, p. 135-143, maio/ago. 2004.

PALUDO, S. S.; KOLLER, S. H. Resiliência na rua: um estudo de caso. Revista Psicologia: Teoria e Pesquisa, Brasília, v. 21, n. 2, p. 187-195, maio/ago. 2005.

PARANÁ. Secretaria do Estado de Educação. Resolução n. 371/2008. Diário Oficial do Paraná, Curitiba, 2008b. Disponível em: <http://www.dioe.pr.gov.br>. Acesso em: 14 jun. 2009.

Secretaria do Estado da Educação. Instrução no $022 / 2008$ SUEDT/ SEED. Assunto: critérios para a abertura da demanda de horas-aula, do suprimento e das atribuições dos profissionais das Salas de Apoio à Aprendizagem - 5a série do Ensino Fundamental, da Rede Pública Estadual. 2008c. Disponível em: <http://www.diaadia.pr.gov.br/deb/arquivos/File/salas_de_apoio/instrucões /instrucao022.pdf>. Acesso em: 14 jun. 2009.

PASSARELI, P. M.; SILVA, J. A. Psicologia positiva e o estudo do bem-estar subjetivo. Estudos de Psicologia: Campinas, v. 24, n. 4, p. 513-517. Outubro - dezembro de 2007.

PATTO, M. H. S. A produção do fracasso escolar: histórias de submissão e rebeldia. São Paulo: Casa do Psicólogo, 1999.

PESCE, R. P.; ASSIS, S. G.; AVANCI, J. Q. Resiliência: enfatizando a proteção dos adolescentes. Porto Alegre: Artmed, 2006.

PIAGET, J. As origens da I nteligência na Criança. New York: WW Norton \& Company, Inc., 1936.

A equilibração das estruturas cognitivas: problema central do desenvolvimento. Rio de Janeiro: Zahar, 1975.

$\overline{1} \overline{9} \overline{7} \overline{7}$

A tomada de consciência. São Paulo: Melhoramentos EDUSP,

As formas elementares da dialética. Trad. Fernanda Mendes Luiz. Coordenação Lino de Macedo. São Paulo, Casa do Psicólogo, 1980.

PIAGET, J. GARCIA, R. Vers une logique dês significations. Genéve: Mourionde editeur, 1987.

Fazer e compreender. São Paulo, Melhoramentos EDUSP, 1978.

PINHEIRO, D. P. N. A resiliência em discussão. Psicologia em Estudo, v. 9, n. 1, p. 67-75, 2004.

PROENÇA, M. Problemas de aprendizagem ou problemas de escolarização? Repensando o cotidiano escolar à luz da perspectiva histórico-crítica. In: OLIVEIRA, M. K.; SOUZA, D. T. R.; REGO, Y. C. (Orgs.). Psicologia, educação e as temáticas da vida contemporânea. São Paulo: Moderna, 2002. p. 177-195.

SAPIENZA, G.; PEDROMÔNICO, M. R. M. Risco, proteção e resiliência no desenvolvimento da criança e do adolescente. Revista Psicologia em Estudo, Maringá, v. 10, n. 2, p. 209-216, maio/ago. 2005.

SELIGMAN, M. E. P. Felicidade autêntica: usando a nova psicologia positiva para a realização permanente. Rio de J aneiro: Objetiva, 2004.

SELIGMAN, M. E. P.; CSIKSZENTMIHALYI, M. Positive psychology: an introduction. American Psychologist, v. 55, n. 1, p. 5-14, 2000. 
SELIGMAN, M. E. P.; STEEN, T. A.; PARK, N.; PETERSON, C. Positive Psychology progress: empirical validation of interventions. American Psychologist, v. 60, n. 5, p. 410-421, 2005.

SMITH, C.; STRICK, L. Dificuldades de aprendizagem de $\mathbf{A}$ a Z: um guia completo para pais e educadores. Porto Alegre: Artmed, 2001.

SOUZA, A. R. M.; SISTO, F. F. Dificuldades de aprendizagem em escrita, memória e contradições. Psicologia Escolar e Educacional, Campinas, v. 5, n. 2, p. 39-48, dez, 2001.

TAVARES, J.; YUNES, M. A. M. ; SZYMANSKI, H.; PEREIRA, A. M. S.; RALHA-SIMÕES, H. CASTRO, M. A. D. de. Resiliência e educação. 3. ed. São Paulo: Cortez, 2002.

YIN, R. K. Estudo de caso: planejamento e métodos. 3. ed. Porto Alegre: Bookman, 2005.

YUNES, M. A. M. Psicologia Positiva e Resiliência: o foco no indivíduo e na família. Psicologia em Estudo, v. 8, n. SPE. Acesso em: 20 de abril de 2010.

ZIBETTI, M. L. T.; SOUZA, F. L. F. da; QUEIRÓZ, K. J. M. Quando a escola recorre à psicologia: mecanismos de produção, encaminhamento e atendimento à queixa na alfabetização. Estudos e Pesquisas em Psicologia, v. 10, n. 2. p. 490-506, agosto 2010.

\section{Endereço para correspondência}

\section{Francismara Neves de Oliveira}

Rua Jerusalém, 99. Apto 302. Bloco 2. Residencial do Lago.

Endereço eletrônico: francis.uel@gmail.com

\section{Lino de Macedo}

Rua Acangueruçu, 204. VI. Pirajuçara, CEP 05579-021, São Paulo- SP, Brasil

Endereço eletrônico: limacedo@me.com

Recebido em: 07/05/2010

Aceito para publicação em: 19/09/2010

Reformulado em: 09/09/2010

Acompanhamento do processo editorial: Adriana Benevides Soares

\section{Notas}

* Departamento de Educação/ Área de Psicologia da Educação e Programa de Mestrado em Educação Escolar da Universidade Estadual de Londrina - UEL. ** Departamento de Psicologia da Aprendizagem, do Desenvolvimento e da Personalidade. Programa de Pós Graduação em Psicologia do Instituto de Psicologia da USP. 